\title{
Análise da percepção de justiça no trabalho: 0 caso de uma instituição pública
}

\section{RESUMO}

O presente estudo é resultado de uma pesquisa sobre a percepção de justiça dos servidores de uma instituição pública esfera judiciária estadual localizada no Estado do Paraná. A pesquisa caracterizou-se como pesquisa descritiva, onde os dados foram coletados por meio de um survey. A avaliação permitiu identificar por meio da percepção dos servidores, alguns aspectos de grau forte, indiferentes e frágil, podendo assim diagnosticar possíveis motivos que contribuem ou não para a percepção dos servidores quanto à justiça no ambiente de trabalho. Para a aplicação e apuração dos resultados foram adotados os critérios apresentados por Gomide Jr. e Siqueira (2008). A coleta de dados ocorreu em um corte transversal no mês de julho de 2014 no próprio ambiente da instituição em estudo. Participaram da pesquisa 102 dos 140 servidores da instituição. Diante dos resultados obtidos identificou-se que as percepções sobre justiça distributiva apresentaram-se divididas em aproximados percentuais, sendo estes, entre os graus extremos avaliados (frágil e forte), onde 48 (47\%) dos pesquisados avaliaram a distribuição de compensação e recompensas de forma positiva como um fator forte dentro da instituição e outros 41 (41\%) consideraram um fator de fragilidade, ou seja, como um ponto negativo. Considerando a percepção de justiça procedimental apresentada por todos os servidores pesquisados, os resultados encontrados apontam uma percepção de grau frágil, pois 45 (44\%) dos servidores indicaram estar insatisfeitos com os procedimentos utilizados pela instituição. Cabe ressaltar que os resultados da pesquisa sugerem um grau significante de insatisfação dos servidores com a percepção de justiça em sua instituição de trabalho.

Palavras-chave: Comportamento Organizacional. Justiça no ambiente de trabalho. Instituição Pública.

Adilson Carlos da Rocha

Gilberto Francisco Ceretta

Mestre em Administração. 


\section{INTRODUÇÃO}

Desde o surgimento dos estudos da Psicologia Social da Justiça, na década de 1960, os pesquisadores vêm se preocupando em demonstrar o papel crucial que os valores, crenças e sentimentos sobre o que é justo ou injusto têm sobre as ações humanas, bem como também nos ambientes organizacionais.

No ambiente organizacional contemporâneo no qual as empresas se encontram, o conceito de percepção de justiça é um fenômeno extremamente importante. Afinal os trabalhadores, seja de maneira individual ou coletiva, desenvolvem percepções sobre justiça no seu ambiente de trabalho, as quais influenciam diretamente no vínculo e compromisso dos colaboradores com os resultados da sua organização.

Os estudos que abordam esse tema contribuem consideravelmente na compreensão das diversas variáveis por meio das quais as pessoas percebem a justiça que ocorre em seus locais de trabalho. Esse tema vem ocupando há muitos anos um lugar central nas preocupações dos pesquisadores que buscam analisar a relação sobre as atitudes e comportamento dos membros organizacionais. As pesquisas atuais buscam abordar o tema sobre duas perspectivas: a justiça distributiva e a justiça de procedimentos.

Enquanto a percepção de Justiça Distributiva avalia o quanto o empregado percebe justiça na distribuição de recursos organizacionais, a percepção de Justiça de Procedimentos busca compreender a percepção do quanto a organização adota ações justas em seus processos decisórios sobre distribuição de recursos entre seus colaboradores.

Analisando alguns estudos que visam compreender a percepção de justiça no trabalho emergem alguns questionamentos como: Qual é a percepção de justiça dos trabalhadores que desenvolvem atividades em uma instituição que compõe o sistema judiciário? Diante desses questionamentos, esse estudo teve como base a seguinte questão norteadora: Qual é a percepção de justiça no trabalho, nos aspectos distributivos e de procedimentos, apresentadas pelos servidores públicos de uma instituição pública do poder judiciário estadual?

No intuito de responder esse questionamento o presente estudo teve como objetivo analisar como se encontram configuradas as variáveis de justiça no trabalho, de acordo com a percepção dos servidores públicos atuantes nessa instituição pública.

\section{PERSPECTIVA CONCEITUAL SOBRE JUSTIÇA}

O termo Justiça remete a um conceito de grande complexidade, que possui inúmeras definições provenientes de suas perspectivas e abordagens variadas. De acordo com Meireles (2006), este tema vem sendo estudado ao longo dos anos por várias áreas como a Filosofia, o Direito, a Sociologia, as Ciências Políticas, a Economia e a Psicologia. Estudos esses que contribuem para o entendimento de conceito de justiça, para a compreensão de suas funções nos diferentes sistemas que existem na sociedade humana, e para entender qual sua influência sobre as ações humanas, sejam elas individuais ou coletivas.

Desde 1960, a psicologia social da justiça vem se preocupando em demostrar o papel que os valores, crenças e sentimentos têm sobre a definição do que é justo ou injusto sobre as ações humanas (PEREIRA, 2008).

O maior corpo teórico desenvolvido a respeito de Justiça, certamente é proveniente do Direito, pois este é seu objeto de estudo primordial. Essa área de conhecimento conceitua a Justiça como equidade, bem-estar e reconhecimento. A justiça é a base para todas as virtudes, considerada virtude moral e consiste na obediência às leis e no bom relacionamento com os cidadãos (ANDRADE, 2010).

Na década de 1960, surgiram os primeiros estudos a respeito de justiça no trabalho, representado na literatura por Adams (1963). Este estudo identificou que indivíduos que se sentiam em situações injustas, desenvolveram maneiras comportamentais com intuito de modificar tal situação (FILENGA; SIQUEIRA, 2006).

O estudo da justiça é de fundamental importância para a análise de questões vinculadas aos aspectos político, social e econômico de uma sociedade organizada, bem como de uma organização (MENDONÇA, 2003).

Até meados dos anos de 1970, os pressupostos de Adams (1963) ficaram restritos à Psicologia Social, quando então o escopo de seu trabalho foi ampliado, voltado para a discussão dos impactos que a percepção de justiça causava no desempenho produtivo de um grupo de pessoas. Deste modo os estudiosos passaram a analisar este novo fenômeno no ambiente organizacional, buscando compreender os critérios de recompensas percebidas como justas e o impacto da distribuição destas sobre o desempenho dos grupos em tarefas preestabelecidas (PAIVA; LEITE, 2011).

De acordo com Siqueira e Gomide Jr. (2004), diversas pesquisas realizadas nas últimas décadas demonstram que as variáveis que determinam vínculos da organização com os trabalhadores que nela atuam, são fundamentais para a compreensão do desempenho dos indivíduos, o que gerou diversas investigações 
empíricas, controvérsias teóricas e metodologias para estudar o assunto.

Segundo Mendonça (2003), tornou-se primordial os debates sobre direitos humanos e concepções que defendem o fim das injustiças sociais que ocorrem no local de trabalho. Pesquisadores interessados em comportamento organizacional direcionam seus estudos, buscando compreender as causas e as consequências dos comportamentos bem aceitos nas organizações.

Diante da grande competitividade do contexto organizacional o perfil das pessoas se altera, juntamente com suas relações com as organizações e percepções das ações praticadas pelas mesmas. Percebe-se que de um lado, as organizações buscam diferenciar o desempenho das pessoas de acordo com suas competências ou influência nos objetivos estratégicos do negócio, mudando seus critérios de remuneração e recompensas oferecidas aos funcionários. E de outro lado, os funcionários ganham autonomia para criticar as formas adotadas pela organização para diferenciar, reconhecer e recompensar seu desempenho no trabalho (ANDRADE; STEFANO, 2011).

No caso do serviço público deve-se somar a estas questões a estabilidade dos servidores. Esta garante ao indivíduo uma segurança considerada quase inexistente no setor produtivo privado, mas que pode gerar acomodação e outros comportamentos (negativos) questionáveis quanto às consequências e repercussões dos trabalhos realizados, por isso a grande preocupação de organizações em relação aos impactos causados pelo comportamento das pessoas na produtividade destes setores e suas percepções a respeito da justiça no trabalho (PAIVA; LEITE, 2011).

Estas atitudes de acordo com Andrade e Stefano (2011) influenciam diretamente a percepção sobre justiça distributiva nas organizações. Com o passar do tempo passou-se a considerar que justiça também depende dos procedimentos adotados e os estudos passaram a combinar justiça distributiva e procedimental.

Rawls (1971) é considerado ainda o principal nome quando se trata da teoria da justiça. Sua obra foi desenvolvida com o propósito de descrever princípios e procedimentos que ajudassem o Estado a resolver os problemas de desigualdade entre os indivíduos. Deste modo o conceito de justiça envolve pelo menos dois conceitos centrais: (i) a distribuição social de bens escassos, e (ii) o procedimento escolhido para selecionar o critério de distribuição (GOMIDE JÚNIOR, 2001).

A partir da teoria da justiça são determinados princípios de justiça social, os quais têm como objetivo determinar direitos e deveres das instituições sociais. Rawls (1971) determina que a cooperação social deve ser embasada em três princípios: o primeiro diz respeito a normas e procedimentos que devem ser legitimados para regular conduta dos indivíduos; o segundo se refere a ideia de equidade na cooperação, que deve ser recíproca e mútua, a fim de adquirir e dividir esforços equitativamente; $\mathrm{e}$, o terceiro, prevê que cooperação social requer uma ideia de vantagem racional, ou seja, quando os participantes da cooperação social consideram o esquema sob seu ponto de vista tendem a obter algo para si (GOMIDE JÚNIOR, 2001).

Assim, afirma-se que justiça e comprometimento são fenômenos fundamentais no ambiente organizacional. Então, a justiça no trabalho pode ser compreendida em duas vertentes clássicas, distributiva e procedimental.

As duas vertentes abordam aspectos que estariam presentes nos indivíduos ao efetuarem avaliações de justiça. Para o indivíduo considerar algo justo, há a necessidade da presença de determinados fatores que se dividem em percepção de justiça distributiva, a qual trata de quão justa o mesmo percebe as compensações que recebe da empresa como retorno para seus esforços investidos no trabalho e, a percepção de justiça de procedimentos, uma medida unidimensional onde o indivíduo avalia quão justo ele percebe as condições e procedimentos que norteiam as políticas de distribuição de recursos na organização que o emprega (GOMIDE JR.; SIQUEIRA, 2008).

Já o termo justiça organizacional foi estudado por Greenberg (1990), a partir de estudos organizados do final da década de 1980, a respeito das percepções e reações às justiças e injustiças que ocorrem vindas da organização em relação aos seus empregados. Deste modo justiça organizacional pode ser compreendida como a psicologia da justiça aplicada aos ambientes organizacionais (ASSMAR; FERREIRA; SOUTO, 2005). Esses autores relatam também que a partir de 1990 as pesquisas sobre o assunto focaram principalmente em compreender sua complexidade, as diferentes dimensões e seus impactos na organização. O Quadro 1 apresenta os principais conceitos a respeito das dimensões de justiça e seus principais estudiosos. 
Quadro 1 - Dimensões de justiça organizacional

\begin{tabular}{|c|c|c|}
\hline Dimensões de Justiça & Caracterização & $\begin{array}{l}\text { Principais } \\
\text { Estudiosos }\end{array}$ \\
\hline Distributiva & $\begin{array}{l}\text { Primeira dimensão estudada pelos cientistas } \\
\text { organizacionais. Seu foco é no conteúdo, ou seja, na } \\
\text { justiça dos fins alcançados ou obtidos sejam eles positivos } \\
\text { ou negativos (ex: salários, lucros, resultados de avaliações } \\
\text { de desempenho ou sanções). }\end{array}$ & Adams, 1965 \\
\hline Procedimental & $\begin{array}{l}\text { Seu foco é o processo, ou seja, na justiça dos meios } \\
\text { usados para alcançar os fins. (ex: procedimentos usados } \\
\text { para movimentação salarial e bonificações, processos } \\
\text { disciplinares, sistemas de avaliação de desempenho, } \\
\text { processos de recrutamento e seleção). }\end{array}$ & $\begin{array}{l}\text { Thibat e Walker, } \\
1975 \text { e 1978; Lind e } \\
\text { Tyler, 1988. }\end{array}$ \\
\hline $\begin{array}{l}\text { Interacional Social/ } \\
\text { Interpessoal }\end{array}$ & $\begin{array}{l}\text { Trata da qualidade da interação entre empregados e } \\
\text { superiores ou decisores, reflete o grau de adoção de um } \\
\text { tratamento digno e respeitador para com os funcionários. } \\
\text { (ex: o gestor age com dignidade e respeito?). }\end{array}$ & $\begin{array}{l}\text { Bies e Moag, 1986; } \\
\text { Tyler e Bies, 1990; } \\
\text { Greengberg, 1993; } \\
\text { e Rego, 2000. }\end{array}$ \\
\hline $\begin{array}{l}\text { Interacional Social/ } \\
\text { Informacional }\end{array}$ & $\begin{array}{l}\text { Reflete a qualidade da interação com os gestores/ } \\
\text { decisores, sobre o grau em que o superior informa, explica } \\
\text { e justifica as decisões que afetam as pessoas. (ex: oferece } \\
\text { justificações aos indivíduos afetados pelas decisões?). }\end{array}$ & $\begin{array}{l}\text { Greengberg e } \\
\text { McCarty, 1990; } \\
\text { Greengberg, 1993; } \\
\text { Konovsky, 2000; } \\
\text { Rego, 2000. }\end{array}$ \\
\hline
\end{tabular}

Fonte: Adaptado de Andrade e Stefano (2011, p. 5).

Conforme apresentado no Quadro 1, como complemento aos diferentes conceitos sobre dimensões de justiça dentro das organizações, Rego (2002) amplia o pensamento e conceito de justiça interacional social e interpessoal, incluindo também a função informacional.

De acordo com vários estudos citados por Rego (2002) é certo que as pessoas mais satisfeitas são aquelas que desenvolvem mais facilmente o comprometimento afetivo com a organização. Tendo tarefas enriquecidas e não rotineiras, oportunidades de promoção, apoio dos colegas, e que participam da tomada de decisões. Essas pessoas veem cumpridas as expectativas que mantinham antes de entrar para o trabalho, criam valores mais congruentes com os da organização, percebendo que a mesma os valoriza e cuida do seu bem-estar, portanto, tem percepções positivas de justiça, principalmente procedimental.

\subsection{Justiça distributiva}

Desde os anos de 1960 estudiosos relataram justiça distributiva como o princípio de que o que é justo é proporcional, onde o homem espera receber suas recompensas de forma proporcional às relações de troca que estabelece com os demais indivíduos. Deste modo o termo justiça distributiva vem com a ideia de que uma distribuição só é justa quando é proporcional às contribuições de cada um, influenciando o investimento no ganho ou benefício (MEIRELES, 2006).

Este foi o ponto de partida para o entendimento dos conceitos atuais sobre justiça distributiva, a qual se trata de acordo com Filenga e Siqueira (2006) da percepção de justiça dos trabalhadores quanto às distribuições obtidas da organização em face de seus esforços.

Para Dela Coleta e Siqueira (1986), a justiça distributiva tem grande influência na atitude dos funcionários, fazendo com que os resultados obtidos numa situação de trabalho representem o ponto principal que influencia o modo de pensar e agir. Um de seus estudos sobre indivíduos que se percebiam como super-recompensados chegou as seguintes conclusões: estes indivíduos têm preferência por aumentar suas contribuições; predileção por não diminuir seus resultados; convencer os colegas a aumentar seus investimentos, colaborando com eles se for o caso; e, ainda, considerar inadequado abandonar a situação de trabalho.

A justiça possui diversas relações, a justiça social relaciona-se com a justiça organizacional e esta, por sua vez, desempenha papel fundamental no funcionamento eficaz das organizações. E nos estudos sobre justiça distributiva identificou-se que indivíduos que consideravam injustos os resultados recebidos poderiam apresentar resultados muito ruins e negativos em relação ao esperado pela organização, resultados esses como insatisfação, pior desempenho individual ou coletivo e menores índices de bom comportamento (FILENGA; 


\section{SIQUEIRA, 2006).}

No campo das organizações de acordo com Pereira (2008), o conceito de justiça distributiva diz respeito à percepção de justiça sobre as recompensas que alguém recebe de uma troca ou interação social, a qual é vista como além de distribuição econômica de recompensas, pela distribuição de condições e recompensas que afetam o bem-estar das pessoas, incluindo aspectos psicológicos, fisiológicos, econômicos e sociais.

Essa percepção pode ser negativa, de acordo com Covacs (2006), quando ocorre diversidade entre a percepção de como um assunto está sendo tratado e de como se imagina que deveria ser tratado. Segundo o autor, a iniquidade só existe quando alguém percebe que a razão dos resultados dos outros e seus investimentos não é igual.

E, em geral, uma grande variedade de experimentos forneceu suporte às prescrições da teoria da equidade: funcionários menos remunerados tendem a ser menos produtivos e menos satisfeitos e aqueles bem remunerados tendem a ser mais produtivos e menos satisfeitos do que os funcionários equitativamente remunerados (SPINELLI, 2010).

Quanto às dimensões da justiça de distribuição, Pereira (2008) afirma a existência de conceituações que se apoiam em concepções referentes à macrojustiça (foco no social) a qual pressupõe a validação da utilidade para assegurar que a distribuição de recursos sociais aconteça de maneira justa principalmente no nível de sociedade mais do que no nível individual; a microjustiça (foco no indivíduo), a teoria que defende o princípio de que todos têm o mesmo direito desde que esse seja proporcional aos esforços desempenhados, isto é, por mérito; como, também, em termos de unidade ou multidimensionalidade (igualdade, equidade, liberdade, oportunidade, necessidade).

Um tema bastante frequente na literatura quando se investiga a percepção de justiça na distribuição de recompensas é a expectativa dos empregados versus retorno organizacional. Dentre diversos trabalhos Gomide Jr. e Siqueira (2008) destacam os estudos de Witt e Wilson (1990), Witt e Broach (1992) e os estudos de Paz (1993). Nestes diversos estudos foi possível identificar que empregados que percebem como justos os retornos organizacionais (salários, benefícios, avaliações de desempenho, dentre outros) são aqueles mais comprometidos com suas organizações e também aqueles que possuem expectativas positivas em relação a estes retornos, além de apresentarem altos níveis de satisfação no trabalho (GOMIDE JR.; SIQUEIRA, 2008)

Portanto, cabem às organizações que buscam aplicar estratégias de mudança organizacional, proporcionar condições ambientais que permitam o desenvolvimento da justiça distributiva, uma vez que ela afeta no modo significativo seja este positiva ou negativamente, a realização de suas metas (FILENGA; SIQUEIRA, 2006).

\subsection{Justiça de procedimentos}

De acordo com Filenga e Siqueira (2006) os estudos a respeito de justiça de procedimentos tiveram início na década de 1970, quando Rawls (1971) desenvolveu a obra "Uma Teoria da Justiça", a qual trata da concepção de justiça dos trabalhadores em relação aos meios adotados pela organização ao definir o quanto cada empregado deve receber por seu esforço realizado no trabalho.

Os primeiros trabalhos sobre percepção de justiça dos procedimentos investigaram os fatores que levariam os indivíduos a perceberem como justas as etapas anteriores à distribuição de recompensas.

De acordo com Gomide Jr. e Siqueira (2008), os procedimentos seriam percebidos justos quando antecedessem a seis condições: (i) houvesse consistência das regras utilizadas ao longo do tempo e independentemente das pessoas as quais estas regras se dirigissem; (ii) houvesse supressão dos vieses determinados por atitudes ou opiniões das pessoas responsáveis pelas tomadas de decisão; (iii) houvesse acurácia nas informações prestadas aos indivíduos afetados pelas decisões tomadas; (iv) houvesse resultados positivos nas decisões; (v) houvesse representatividade dos indivíduos afetados pelas decisões na formação do grupo de pessoas responsáveis pelas tomadas de decisões, e; (vi) houvesse a manutenção de padrões éticos e morais.

As pessoas demostram conferir grande importância à maneira como são usados os procedimentos em que elas estão inseridas. Desta forma, entende-se que a justiça de procedimentos é a vertente da justiça no trabalho que tem foco no processo, isto é, está focada nos métodos usados para alcançar os objetivos pretendidos pela organização. (REGO, 2000).

De acordo com Gomide Jr. (1999) a percepção de justiça de procedimentos se define pela crença que o empregado apresenta, de que são justos os meios utilizados na determinação do montante que receberá em consequência do seu trabalho e contribuição para a empresa.

Muitos autores se interessaram em investigar se os tipos de justiça diferem na maneira como influenciam as reações e comportamentos dos trabalhadores. Como relata Spinelli (2010), em geral, os resultados indicam que a justiça procedimental pode ser um preditor mais importante do que a justiça distributiva no que se refere à avaliação da organização e seus representantes, como comprometimento organizacional, lealdade à 
organização e confiança no superior. Ao contrário, a justiça distributiva está mais bem relacionada a resultados pessoais percebidos, tais como satisfação com os salários.

No contexto apresentado, a justiça de procedimentos abrange aspectos estruturais muito importantes tais como: ter voz no processo decisório e aspectos sociais como a justificação aos indivíduos afetados pelas decisões (SOUSA, 2005).

\section{PROCEDIMENTOS METODOLÓGICOS}

Este estudo se caracteriza como uma pesquisa descritiva, que de acordo com Gil (2010), possibilita uma aproximação conceitual, onde se analisam os fatos, confrontando a visão teórica com a realidade, tornando-se necessário traçar um modelo conceitual e operativo da pesquisa.

Os dados foram coletados por meio de uma survey (questionário). Quando se questionam pessoas em uma survey, devem-se buscar suas ideias em relação a questões ou aspectos importantes do assunto tratado, descobrindo o que é importante dentro do conhecimento destas pessoas (COOPER; SCHINDLER, 2003).

Para este procedimento foi aplicado um questionário para verificar a percepção dos servidores quanto percepção de justiça no ambiente de trabalho. $O$ referido instrumento de pesquisa aplicado foi desenvolvido por Gomide Jr. e Siqueira (2008), baseados nos estudos de Siqueira et al. (1996) e Gomide Jr., Lima e Faria Neto (1996).

Cabe ressaltar que não houve necessidade de realizar um pré-teste para instrumento, pois o mesmo já foi testado cientificamente por seus autores, tendo sido comprovada, portanto, sua eficácia enquanto instrumento de coleta de dados para avaliar a percepção de justiça no ambiente de trabalho.

A coleta de dados ocorreu em um corte transversal no mês de julho de 2014 no próprio ambiente de trabalho na instituição jurídica. $O$ instrumento foi entregue a todos os 140 servidores que atuam na instituição objeto desse estudo. Porém, participaram da pesquisa 102 (43 efetivos e 59 contratados) dos 140 servidores de uma instituição pública do sistema judiciário estadual, localizada na cidade de Francisco Beltrão, Estado do Paraná.

\subsection{Escalas psicométricas}

Para alcançar os objetivos desse estudo foram utilizadas duas escalas psicométricas, sendo: a Escala de Percepção de Justiça Distributiva desenvolvida por Siqueira et al. (1996) e a Escala de Percepção de Justiça de Procedimentos desenvolvida pelos pesquisadores Gomide Jr., Lima e Faria Neto (1996).

Enquanto a primeira avalia o quanto o trabalhador percebe justiça na distribuição de recursos organizacionais, a segunda identifica a percepção do quanto a empresa adota ações justas em seus processos decisórios sobre distribuição de recursos entre seus colaboradores (GOMIDE JR.; SIQUEIRA, 2008).

\subsubsection{Escala de Percepção de Justiça Distributiva - EPJD}

A escala de Percepção de Justiça Distributiva (EPJD), uma medida unidimensional, elaborada para avaliar as crenças do trabalhador acerca de quão justas ele percebe as compensações que recebe da empresa como retorno para seus investimentos no trabalho. (GOMIDE JR.; SIQUEIRA, 2008). Para representar essas crenças, os autores da escala desenvolveram cinco afirmativas que abordavam aspectos relacionados a responsabilidade, a experiência profissional, aos esforços no trabalho, a qualidade do trabalho e o estresse a que o trabalhador é submetido durante a realização de suas atividades.

De acordo com Gomide Jr. e Siqueira (2008), o processo de construção iniciou-se com uma validação fatorial, na qual foi submetida à avaliação semântica para se verificar a compreensão de suas instruções, de seus itens (cinco frases) e da escala de respostas composta por sete pontos, sendo: $(1$ = discordo totalmente; 2 $=$ discordo moderadamente; 3 discordo levemente; $4=$ nem concordo, nem discordo; 5 = concordo levemente; $6=$ concordo moderadamente; $7=$ concordo totalmente).

\subsubsection{Escala de Percepção de Justiça de Procedimentos - EPJP}

A escala de Percepção de Justiça de Procedimentos (EPJP) também é uma medida unidimensional, construída para avaliar as crenças do trabalhador acerca de quão justas ele percebe as condições ou os procedimentos que norteiam as políticas de distribuição de recursos na organização que o emprega (GOMIDE JR.; SIQUEIRA, 2008). Para representar essas crenças, Gomide Jr., Lima e Faria Neto (1996). Desenvolveram seis afirmativas que tinham como objetivo retratar as seis condições relatadas nos estudos de Leventhal (1980), sendo essas relacionadas a procedimentos percebidos como justos pelos trabalhadores. 
Como na construção da EPJD, a construção da EPJP foi desenvolvida por meio de um processo de validação fatorial e submetida à avaliação semântica para se verificar a compreensão de suas instruções, de seus itens (seis frases) e da escala de respostas com sete pontos da mesma forma a escala EPJD.

\subsubsection{Aplicação e apuração dos resultados}

Para a aplicação e apuração dos resultados foram adotados os critérios elencados por Gomide Jr. e Siqueira (2008), os quais orientam que a aplicação, apuração dos resultados e interpretação das duas escalas poderá ser feita de forma individual ou coletiva. Os autores ressaltam que deve haver alguns cuidados no momento da aplicação, atentando para que os participantes respondentes tenham entendido as instruções e o modo de indicar suas respostas.

Na fase de interpretação dos resultados obtidos pela aplicação de cada escala, Gomide Jr. e Siqueira (2008) orientam que se deve considerar quanto maior o valor obtido, maior será a percepção do trabalhador sobre o quanto a organização recompensa-o de maneira justa (percepção distributiva) e de quanto à organização possui condições ou procedimentos justos na determinação de seus critérios de alocação de recursos (percepção procedimental). Valores entre 5 e 7 tendem a representar a percepção de justiça, tornando-se este mais forte à medida que o escore se aproxima de 7 . Valores entre 1 e 3,9 revelam percepção frágil. A percepção torna-se mais frágil ou praticamente inexistente à medida que se aproxima de 1. Valores entre 4 e 4,9 podem representar uma certa indiferença ou desconfiança do trabalhador naquele momento acerca de recompensas, condições ou procedimentos justos ofertados pela organização.

\section{ANÁLISE E DISCUSSÃO DOS RESULTADOS}

Nesta seção são apresentados os resultados com base nos coletados, compreendendo perfil demográfico da amostra, os aspectos inerentes à justiça distributiva e procedimental, de acordo com a percepção dos servidores participantes da pesquisa.

\subsection{Perfil demográfico do estudo}

Os participantes da pesquisa são servidores de todos os setores e cartórios existentes na instituição pública do sistema judiciário estadual, localizada na cidade de Francisco Beltrão, Estado do Paraná, ou seja, servidores efetivos e contratados, sendo escrivães, juízes, promotores, técnicos judiciários e também estagiários. Identificando o tempo de trabalho dos servidores pesquisados, observou-se que há uma maior concentração de pessoas que trabalham a um período entre quatro e dez anos na instituição, totalizando 23\% da amostra, seguidas por uma porcentagem de $19 \%$ de servidores que trabalham a menos de um ano na instituição.

Os servidores que trabalham na instituição a um período entre três e quatro anos são 18\% dos pesquisados, $15 \%$ trabalham mais de dez anos na Instituição e o restante dos pesquisados estão na Instituição a um período entre um a dois anos e dois a três anos, que somam um total de 12\% e 13\% respectivamente. Estes resultados demostram que a maioria da amostra pesquisada trabalha na organização há mais de 2 anos.

Cabe destacar que 20 pesquisados trabalham a menos de um ano na instituição, o que se deve ao fato de muitos destes serem estagiários ou terem assumido o concurso no último ano. Os dados demonstram que não há uma concentração significativa em um único período, o que evidência uma renovação periódica dos servidores na instituição.

Quanto à qualificação por meio da escolarização dos servidores, os resultados obtidos evidenciam um nível elevado, tendo em vista que $31 \%$ dos servidores já estão cursando a graduação e 59\% já possuem formação de nível superior, com graduação completa, Pós-Graduação incompleta ou Pós-Graduação completa.

Os demais servidores que somam um total de 10\% da amostra possuem apenas formação básica. De acordo com os resultados do estudo realizado por Andrade e Stefano (2011), o grau de percepção para Justiça Distributiva diminui significativamente com o aumento do nível educacional, sendo assim, quanto maior o grau de escolaridade dos respondentes menor tende a ser a percepção de Justiça Distributiva. O mesmo estudo mencionado destaca que essa relação pode ser atribuída ao fato de que o aumento do grau de escolaridade pode influenciar também o nível de criticidade a respeito das políticas e práticas organizacionais e, como consequência, também altera a percepção de como acontece a distribuição dos bens escassos na organização.

A análise dos dados inerentes à percepção de justiça foi dividida em três partes, dentre elas buscou-se analisar a percepção de justiça distributiva pelos servidores efetivos, dos servidores contratados e, ao final, da amostra como um todo. 


\subsection{Percepção de justiça distributiva - servidores efetivos}

Este item apresenta os dados apurados em relação à percepção de justiça distributiva pelos servidores efetivos da instituição. Os quais totalizam $42,16 \%$ da amostra, o que correspondem a 43 dos respondentes.

Os resultados obtidos indicam que 21 dos servidores efetivos pesquisados (49\%) perceberam as compensações que recebem da instituição de forma positiva, sendo considerado então, um forte grau de percepção de acordo com a escala psicométrica adotada. Porém, a percepção de grau frágil indicado pelo outro extremo da escala, indicou um resultado significativo, pois 16 dos servidores (37\%) indicaram não estarem de acordo com as compensações utilizadas.

Os demais servidores efetivos representados por 6 respondentes, ou seja 14\%, apontaram opinião indiferente à percepção de justiça distributiva. Diante dos resultados apurados para este item, é possível concluir que a maioria dos servidores efetivos considera a justiça distributiva em sua instituição com grau forte, o que pressupõe que estes estejam sendo recompensados de maneira justa pela organização.

\subsection{Percepção de justiça distributiva - servidores contratados}

Quanto a percepção de justiça distributiva apresentada pelos servidores contratados, os quais representam $59(57,84 \%)$ dos respondentes, verificou-se que os resultados são significativos entre as extremidades de percepção forte e frágil, ou seja, em percentuais tiveram resultados equilibrados, sendo que 27 (46\%) destes servidores perceberam a compensação por seu trabalho como justa, e outros 25 (42\%) perceberam como não justa, ou seja, como um fator frágil na instituição.

Os demais servidores contratados, que representam 12\%, indicaram uma percepção indiferente ou sem importância à forma como a instituição recompensa as pessoas por seus esforços realizados na atividade laboral. Os resultados apresentados pelos servidores contratados - não efetivos - sugerem que esses servidores apresentam uma percepção de justiça distributiva de forma negativa e frágil comparado à percepção dos servidores efetivos pesquisados.

De acordo com Covacs (2006), os sentimentos de injustiça ocorrem quando um trabalhador percebe que há diversidade entre como um assunto está sendo tratado e de como se imagina que deveria ser tratado, e, essa iniquidade só existe quando alguém percebe que a razão entre os resultados dos outros e os esforços por eles feitos não são tratados de forma igualitária.

\subsection{Percepção de justiça distributiva - amostra total}

Em uma análise mais ampla sobre a percepção de justiça distributiva indicada por toda a amostra composta pelos servidores de uma instituição pública do sistema judiciário estadual, localizada na cidade de Francisco Beltrão, Estado do Paraná, verificou-se que as percepções apresentaram-se divididas em aproximados percentuais entre os graus extremos avaliados (frágil e forte), onde $48(47 \%)$ dos pesquisados avaliaram a distribuição de compensação e recompensas de forma positiva como um fator forte dentro da instituição, outros 41 (40\%) consideraram um fator de fragilidade, ou seja, como um ponto negativo. Já os demais 13 servidores se mostraram indiferentes quanto a esta dimensão.

De acordo com os resultados apurados pode se concluir que apesar de a maior porcentagem dos respondentes considerarem a dimensão de justiça distributiva como um fator forte dentro da instituição, um número significativo de servidores está insatisfeito com a distribuição de compensação e recompensas propostas pela organização em estudo.

Essa constatação sugere como já identificada em alguns estudos sobre justiça distributiva, que indivíduos que consideram injustos os resultados recebidos podem apresentar resultados ruins e negativos em relação ao esperado pela organização, resultados estes, como insatisfação, pior desempenho individual ou coletivo e menores índices de bom comportamento (FILENGA; SIQUEIRA, 2006).

Quanto à percepção positiva sobre justiça distributiva, Gomide Jr. e Siqueira (2008) desenvolveram estudos nos quais identificaram que empregados que percebem como justos os retornos organizacionais (salários, benefícios, avaliações de desempenho, dentre outros) são aqueles mais comprometidos com suas organizações e também aqueles que possuem expectativas positivas em relação a estes retornos, além de apresentarem altos níveis de satisfação no trabalho.

Segundo Dela Coleta e Siqueira (1986), as percepções positivas sobre os aspectos que envolvem a justiça distributiva têm grande influência na atitude dos trabalhadores, fazendo com que os resultados obtidos numa situação de trabalho representem o ponto principal que pode determinar o modo de pensar e agir. 


\subsection{Percepção de justiça procedimental - servidores efetivos}

Os resultados apresentados pelos servidores efetivos quanto à justiça procedimental demonstram que 20 (46\%) desses servidores avaliaram a essa dimensão como frágil. Outros 14 (33\%) servidores avaliaram os procedimentos utilizados como forte.

Os demais respondentes efetivos, 9 (21\%) demonstraram uma indiferença quanto aos procedimentos utilizados pela instituição. Este resultado indica que a maior parte dos servidores efetivos não está satisfeita com a forma com que a justiça de procedimentos está sendo adotada na instituição em estudo, o que se sinaliza um aspecto negativo.

De acordo com Sousa (2005), é significativa a importância de aspectos que a justiça procedimental abrange, tais como: ter voz no processo decisório e aspectos sociais como a justificação aos indivíduos afetados pelas decisões.

\subsection{Percepção de justiça procedimental - servidores contratados}

A percepção de justiça procedimental demonstrada pelos servidores contratados, também apresentou um resultado negativo. Considerando a amostra de 59 (57,84\%) servidores contratados, desses, 25 (42\%) servidores perceberam a justiça dos procedimentos como frágil, ou seja, consideram que a instituição não adota ações justas em seus processos decisórios sobre distribuição de recursos e regras entre seus colaboradores.

Considerando essa mesma amostra - servidores contratados -, 20 (34\%) indicaram que os procedimentos utilizados parecem ser justos, caracterizando-se desta forma, como um ponto forte dentro da instituição onde desenvolvem suas atividades laborais. Outra parcela representada por 14 (24\%) pesquisados se mostraram indiferentes ou sem relevância à forma como os procedimentos são utilizados.

Esses resultados obtidos para essa parcela da amostra - servidores contratados - de acordo com Sousa (2005) sugerem que a maior parte dos servidores contratados não concorda com as políticas e os procedimentos que norteiam a forma das tomadas de decisões no seu ambiente de trabalho.

\subsection{Percepção de justiça procedimental - amostra total}

Em uma análise mais ampla considerando a amostra total pesquisada, os resultados encontrados apontam uma percepção de grau frágil, pois 45 (44\%) dos servidores indicaram estar insatisfeitos com os procedimentos utilizados pela instituição, o que sugere ser um aspecto preocupante para a organização objeto de estudo.

Dentre todos os servidores participantes do estudo, 34 (33\%), indicaram uma percepção de justiça procedimental como forte. Este resultado sugere que os mesmos consideram justos os procedimentos utilizados em sua instituição de trabalho. Esta satisfação representa de acordo com a Gomide Jr. (1999), que são justos os meios utilizados na determinação do montante que o trabalhador receberá em consequência do seu trabalho e contribuição para a empresa. Os outros 23 servidores demostraram uma percepção de grau indiferente à justiça de procedimentos dentro da instituição.

Comparando os resultados obtidos neste estudo com um dos estudos desenvolvidos por Paiva e Leite (2011) sobre justiça no trabalho, observaram-se semelhanças no grau de fragilidade da percepção de justiça procedimental, onde naquele estudo $58 \%$ do total de pesquisados discordaram de que havia equidade nas políticas e práticas organizacionais quanto aos procedimentos formais de distribuição de recompensas, o que se traduz em uma elevada possibilidade de estar se desenvolvendo dentro da instituição, atitudes e comportamentos retaliatórios, o que também foi alvo da pesquisa mencionada.

Quando a percepção apresentada pelos trabalhadores atinge um grau forte, os mesmos, de acordo com Covacs (2006), desenvolvem um grau maior de comprometimento no trabalho se, as regras utilizadas forem bem definidas explicitando o quanto cada um receberá por seu esforço, se houver participação na tomada de decisão e ausência de vieses por parte de quem decide, além de serem honrados os compromissos estabelecidos pela organização com as pessoas, o que propiciará um ambiente favorável à concorrência de vínculos afetivos do empregado com a organização.

\subsection{Justiça distributiva - médias fatoriais}

Realizando uma análise da amostra total dos servidores para a justiça distributiva, comparando as médias fatoriais apuradas para cada elemento que compõe a escala, buscou-se identificar quais elementos poderiam ter contribuído para os resultados até aqui apresentados. A Tabela 1 apresenta os elementos avaliados, as respectivas médias e o desvio padrão. 
Tabela 1 - Análise das médias fatoriais - Justiça Distributiva

\begin{tabular}{|c|c|c|c|}
\hline Item & Questões / elementos que compõem a EST & Média & $S$ \\
\hline 1 & $\begin{array}{l}\text { Sou recompensado, de maneira justa, por minha } \\
\text { responsabilidade no trabalho. }\end{array}$ & 4,94118 & 1,97922 \\
\hline 2 & $\begin{array}{l}\text { Sou recompensado, de maneira justa, por minha experiência } \\
\text { profissional. }\end{array}$ & 4,54902 & 2,13703 \\
\hline 3 & $\begin{array}{l}\text { Sou recompensado, de maneira justa, por meus esforços no } \\
\text { trabalho. }\end{array}$ & 4,59804 & 2,09318 \\
\hline 4 & $\begin{array}{l}\text { Sou recompensado, de maneira justa, pela qualidade do } \\
\text { trabalho que apresento. }\end{array}$ & 4,55446 & 2,06628 \\
\hline \multirow[t]{2}{*}{5} & $\begin{array}{l}\text { Sou recompensado, de maneira justa, pelo estresse a que sou } \\
\text { submetido durante o meu trabalho. }\end{array}$ & 3,67647 & 2,13487 \\
\hline & Resultado $=\sum_{N} n$ & 4,40588 & 1,89684 \\
\hline
\end{tabular}

Observando as médias individuais para cada questão analisada é possível verificar, por exemplo, que o item 1 (recompensa de maneira justa pela responsabilidade no trabalho) obteve a maior média entre os cinco elementos que compõem a escala. Dessa forma, é possível sugerir que esse elemento tenha contribuído para o resultado de grau forte $(47 \%)$ apresentado pelos pesquisados.

Verificou-se que o item 5 (recompensa de maneira justa pelo estresse que o servidor é submetido durante o seu trabalho) obteve a menor média entre os elementos analisados. Esse resultado pode ter contribuído para o resultado de grau frágil (40\%) indicado pelos servidores estudados.

Situações desagradáveis para as pessoas representam riscos para as empresas. Quem não está satisfeito, não tem comprometimento com a organização, faz o necessário para manter o emprego, mas não se esforça para obter um melhor resultado. $\mathrm{O}$ stress, como apontado nos resultados deste estudo, é um dos maiores motivos para a percepção de grau frágil dos servidores, o qual, de acordo com Lacombe (2005) é causado pela exagerada pressão pelos resultados e o medo de não conseguir um desempenho satisfatório, bem como a falta de controle sobre algumas variáveis importantes para a obtenção dos resultados.

\subsection{Justiça procedimental - médias fatoriais}

Da mesma forma, elaborando uma análise da amostra total dos servidores para a justiça procedimental, comparando as médias fatoriais apuradas para cada elemento que compõe a escala, buscou-se reconhecer quais elementos poderiam ter contribuído para os resultados até aqui demonstrados. A Tabela 2 aponta os elementos avaliados, as respectivas médias e o desvio padrão.

Tabela 2 - Análise das médias fatoriais - Justiça Procedimental

\begin{tabular}{clcc}
\hline Item & \multicolumn{1}{c}{ Questões / elementos que compõem a EST } & Média & S \\
\hline $\mathbf{1}$ & $\begin{array}{l}\text { A Instituição onde trabalho utiliza regras bem definidas. } \\
\mathbf{2}\end{array} \quad \begin{array}{l}\text { A Instituição onde trabalho utiliza as mesmas regras para } \\
\text { todos os empregados. }\end{array}$ & 4,06863 & 1,9814 \\
$\quad \begin{array}{l}\text { A Instituição onde trabalho possui regras que impedem que } \\
\text { as pessoas responsáveis pelas decisões levem vantagens } \\
\text { pessoais. }\end{array}$ & 4,52941 & 2,26775 \\
$\mathbf{4} \quad \begin{array}{l}\text { A Instituição onde trabalho possui regras que foram definidas } \\
\text { a partir de informações precisas. }\end{array}$ & 4,17822 & $\mathbf{2 , 2 1 0 6}$ \\
$\mathbf{5} \quad \begin{array}{l}\text { A Instituição onde trabalho permite a participação dos } \\
\text { empregados na formulação das regras. }\end{array}$ & 3,39216 & 2,02537 \\
$\mathbf{6} \quad \begin{array}{l}\text { A Instituição onde trabalho possui regras que foram } \\
\text { elaboradas com base em padrões éticos. }\end{array}$ & 4,65686 & 1,89577 \\
\hline & $\begin{array}{l}\text { Resultado }=\sum \mathrm{n} \\
\mathrm{N}\end{array}$ & 4,00490 & 1,63391 \\
\hline
\end{tabular}

Fonte: Dados da Pesquisa (2014). 
Observando as médias de forma independente para cada questão analisada é possível verificar, tendo, por exemplo, que o item 6 (a instituição possui regras de trabalho elaboradas com base em padrões éticos) obteve a maior média entre os seis elementos que compõem a escala. Logo, é possível propor que esse elemento tenha contribuído para o resultado de grau forte (33\%) apresentado pelos servidores pesquisados.

Organizações éticas atraem e retém colaboradores éticos e responsáveis, e por meio de seus padrões conquistam o respeito e a confiança de seus stakeholders. Os resultados deste estudo sugerem que a maioria dos servidores percebeu que as ações da instituição estão de acordo com valores válidos em qualquer cultura e situação como a honestidade, a equidade, a justiça e o respeito (LACOMBE, 2005).

Ampliando a análise verificou-se que o item 2 (a instituição utiliza as mesmas regras para todos os empregados) e o item 5 (a instituição permite a participação dos empregados na formulação das regras) atingiram as menores médias entre os elementos analisados. Esses resultados podem estar associados ao resultado de grau frágil (44\%) indicado pelos servidores estudados.

A organização em estudo pode ser considerada burocrática, por isso a existência de participação dos servidores nas decisões e formulações de regras é quase inexistente. De acordo com Wagner III e Hollenbeck (2006), quando ocorrem em conjunto, padronização, formalização e especialização, estes constituem um tipo de estrutura frequentemente chamada de burocrática, na qual são usadas regras e regulamentos para governar o comportamento de seus membros.

\section{CONSIDERAÇÕES FINAIS}

O tema abordado neste estudo contribui consideravelmente na compreensão das diversas variáveis por meio das quais as pessoas perspectivam e percebem a justiça que ocorre em seus locais de trabalho. As pesquisas atuais almejam abordar o tema sobre duas perspectivas: a justiça distributiva e a justiça de procedimentos.

Enquanto a primeira, percepção de Justiça Distributiva, avalia o quanto o empregado percebe justiça na distribuição de recursos organizacionais, a percepção de Justiça de Procedimentos busca compreender a percepção do quanto a organização adota ações justas em seus processos decisórios, sobre distribuição de recursos entre seus colaboradores.

O objetivo do estudo foi analisar como se encontram configuradas as variáveis de justiça no trabalho, de acordo com a percepção dos servidores públicos de uma Instituição Pública do poder judiciário estadual. A avaliação permitiu identificar por meio da percepção dos servidores alguns aspectos de grau forte, indiferentes e frágil, podendo assim diagnosticar possíveis motivos que contribuem ou não para a percepção dos servidores quanto a justiça no ambiente trabalho.

Verificou-se como principais resultados obtidos no estudo, em uma análise geral dos servidores pesquisados, que as percepções sobre justiça distributiva apresentaram-se divididas em aproximados percentuais, sendo estes, entre os graus extremos avaliados (frágil e forte), onde a maior parte dos pesquisados avaliaram a distribuição de compensação e recompensas de forma positiva como um fator forte dentro da instituição e outros consideraram um fator de fragilidade, ou seja, como um ponto negativo.

Considerando a percepção de justiça procedimental apresentada por todos os servidores pesquisados, os resultados encontrados apontam uma percepção de grau frágil, pois, um maior número de servidores indicou estarem insatisfeitos com os procedimentos utilizados pela instituição. Cabe ressaltar que os resultados da pesquisa sugerem um grau significante de insatisfação dos servidores com a percepção de justiça em sua instituição de trabalho.

Ressaltando que as organizações públicas possuem um conjunto de características institucionais que as diferenciam em relação a outras organizações. Os indivíduos que exercem suas funções, no caso da pesquisa em tela, os servidores efetivos, por possuírem a tutela de estabilidade, possuem uma compreensão mais funcionalista no senso de justiça, pois, seguem um regramento normativo enraizado, com pouca flexibilidade, o que transforma em um estado de passividade em relação às justiças organizacionais percebidas.

Em outra perspectiva os servidores contratados, que desempenham suas atividades com um prazo determinado, percebem diferentemente dos efetivos, uma heterogeneidade em relação a essas justiças, envolvidas em um forte invólucro cultural, comum em instituições públicas. Acrescenta-se ainda que as instituições judiciárias pareçam ser constituídas por uma série de rituais próprios, que ocasionam forte apelo ao seguimento das leis constitucionais, invocando um comportamento isento e ético no desempenho das funções.

Como sugestão para futuras pesquisas, indica-se a ampliação do estudo com objetivo de associar a percepção de justiça no trabalho, com outros indicadores de desempenho como, o comprometimento e ética 
dos trabalhadores para com a organização, ou ainda, comparar os resultados obtidos sobre a percepção de justiça em instituições públicas do poder judiciário, possibilitando um aprofundamento sobre o tema nesse ambiente organizacional.

\title{
ANALYSIS OF JUSTICE PERCEPTION AT WORK: THE CASE OF A PUBLIC INSTITUTION
}

\begin{abstract}
This study is the result of a survey on servers perception of fairness in a public sphere state judicial institution. The research was characterized as descriptive, where the data was collected through a survey. The evaluation identified through the perception of servers, some aspects of justice in three degrees: high, indifferent and fragile. Thus we were able to diagnose possible reasons that contribute or not to the perception of servers in what concerns justice in the workplace. For the application and verification of the results, the criteria presented by Gomide Jr. and Smith (2008) were adopted. Data collection occurred in a cross-section in July 2014 at the environment of the institution under study. The participants were 102 of 140 servers of the institution. Given the obtained results, it was found that perceptions of distributive justice appeared divided into percentages approximate, which are among the evaluated extreme degrees (weak and strong), where 48 (47\%) of respondents evaluated the distribution of compensation and rewards positively as a strong factor within the institution, and other $41(41 \%)$ considered a factor of weakness, that is, as a negative point. Considering the perception of procedural fairness displayed by all surveyed servers, the results show a perception of fragile in degree, as 45 (44\%) of the servers indicated they are dissatisfied with the procedures used by the institution. Note that the survey results suggest a significant degree of dissatisfaction of the servers with the perception of fairness in their work institution.
\end{abstract}

Keywords: Organizational behavior. Justice in the workplace. Public institution.

\section{REFERÊNCIAS}

ADAMS, J. S. Toward and understanding of inequity. Journal of Abnormal and Social Psychology, Washington, v. 67, n. 5, p. 422-436, Nov. 1963.

ANDRADE, S. M. Percepção de justiça distributiva no clima organizacional: um estudo sobre organizações brasileiras que buscam se destacar pela qualidade do ambiente de trabalho. 96 p. Dissertação (Mestrado) Faculdade de Economia, Administração e Contabilidade, Universidade de São Paulo, São Paulo, 2010.

ANDRADE, S. M.; STEFANO, S. R. Justiça distributiva: um estudo sobre as variáveis demográficas dos funcionários e sua percepção sobre o ambiente de trabalho. In: Enanpad, 35., 2011, Rio de Janeiro. Anais do XXXV Encontro da ANPAD. Rio de Janeiro: ENANPAD, 2011. p. 01-16.

ASSMAR, E. M. L.; FERREIRA, M. C.; SOUTO, S.O. Justiça organizacional: uma revisão crítica da literatura. Psicologia: Reflexão e crítica, v. 18, n. 3, p. 443-453, 2005.

COOPER, D. R.; SCHINDLER, P. S. Métodos de pesquisa em administração. 7. ed. Porto Alegre: Bookman, 2003.

COVACS, J. M. L. M. Bem-estar no trabalho: o impacto dos valores organizacionais, percepção de suporte organizacional e percepções de justiça. 117 p. Dissertação (Mestrado). Universidade Metodista de São Paulo, São Bernardo do Campo, 2006.

DELA COLETA, J. A.; SIQUEIRA, M. M. M. Situações de iniquidade no trabalho: preferência por soluções cognitivas e comportamentais. Arquivos brasileiros de psicologia, Rio de Janeiro, v. 38, n. 3, p. 1-19, 1986.

FILENGA, D.; SIQUEIRA, M. M. M. O impacto de percepções de justiça em três bases de comprometimento organizacional. Revista de Administração, São Paulo, v. 41, n. 4, p. 431-441, 2006.

GIL, A. C. Como elaborar projetos de pesquisa. 5. ed. São Paulo: Atlas, 2010. 
GOMIDE JUNIOR, S. Antecedentes e consequentes das percepções de justiça no trabalho. 1999. Tese (Doutorado) - Universidade de Brasília, Brasília, Brasil.

GOMIDE JÚNIOR, S. Justiça nas organizações. In: SIQUEIRA, M. M. M.; GOMIDE JÚNIOR, S.; OLIVEIRA, A. F. (Org.). Cidadania, justiça e cultura nas organizações: estudos psicossociais. São Bernardo do Campo: Metodista, 2001. p. 15-102.

GOMIDE JÚNIOR, S.; SIQUEIRA, M. M. M. Justiça no trabalho. In: SIQUEIRA, M. M. (Org.). Medidas do comportamento organizacional: ferramentas de diagnóstico e de gestão. Porto Alegre: Artmed, 2008. p.189197.

GOMIDE Jr., S.; LIMA, D. M.; FARIA NETO, W. Validade discriminante das medidas de percepção de justiça de distribuição e percepção de justiça de procedimentos. In: REUNIÃO ANUAL DA SOCIEDADE BRASILEIRA DE PSICOLOGIA, 26., 1996, Ribeirão Preto. Resumos de comunicações científicas. Ribeirão Preto: Sociedade Brasileira de Psicologia, 1996.

GREENBERG, J. Organizational Justice: Yesterday, Today, and Tomorrow. Journal of Management, v. 16, n. 2, p. 399-432, 1990.

LACOMBE; F. J. M. Recursos humanos: princípios e tendências. São Paulo: Saraiva, 2005.

LEVENTHAL, G.S. What should be done with equity theory? In: GERGEN, K.S.; GREENBERG, J.; WEISS, R.H. (Eds). Social exchange: advances in theory an research. New York: Plenum, 1980, p. 211-239.

MEIRELES, I. A. C. O impacto das percepções de justiça organizacional sobre as vivências de prazer e sofrimento no trabalho. 2006. 99 p. Dissertação (Mestrado) - Universidade Católica de Goiás, Goiânia, 2006.

MENDONÇA, H. Retaliação organizacional: o impacto dos valores e da justiça. 2003. Tese (Doutorado) Universidade de Brasília (UNB), Brasília.

PAIVA, K. C. M.; LEITE, N. E. Justiça no trabalho e atitudes relatorias: um estudo com servidores técnicos administrativos de uma instituição federal de ensino superior. Revista Gestão \& Tecnologia, Pedro Leopoldo, v. 11, n. 1, p. 50-67, jan./jun. 2011.

PAZ, M.G.T. Justiça distributiva na avaliação de desempenho dos trabalhadores de uma empresa estatal. In: REUNIÃO ANUAL DA SOCIEDADE BRASILEIRA DE PSICOLOGIA, 23., 1993, Ribeirão Preto. Resumos de comunicações científicas. Ribeirão Preto: Sociedade Brasileira de Psicologia, 1993.

PEREIRA, J. B. C. A relação entre as dimensões de justiça organizacional e as atitudes dos indivíduos diante da diversidade. 329 f. 2008. Tese (Doutorado em Administração) - Universidade Presbiteriana Mackenzie, São Paulo, 2008.

RAWLS, J. A Theory of justice. Cambridge: Harvard University Press, 1971.

REGO, A. Justiça nas organizações: na senda de uma nova vaga? In: RODRIGUES, S. B; CUNHA, M. P.(Org.). Estudos organizacionais: novas perspectivas na administração de empresas. Uma coletânea luso-brasileira. São Paulo: Iglu, 2000. p. 251-283.

REGO, A. Comprometimento afetivo dos membros organizacionais: o papel das percepções de justiça. Revista de Administração Contemporânea, Curitiba, v. 6, n. 2, p. 209-241, 2002.

SIQUEIRA, M. M. M.; GOMIDE Jr., S. Os vínculos do indivíduo com a organização e com o trabalho. In: ZANELLI, J. C.; BORGES-ANDRADE, J. E.; BASTOS, A., V., B. (Org.). Psicologia Organizacional e Trabalho. Porto Alegre: Artmed, 2004. p. 316-350.

SIQUEIRA, M.M.M. et al. Análise de um modelo pós-cognitivo para intenção de rotatividade. In: Congresso Internacional de Psicologia, 26., 1996, São Paulo. Resumos... São Paulo: Sociedade Interamericana de Psicologia, 1996. 
SPINELLI, R. Q. Um estudo sobre os comportamentos políticos no contexto organizacional. 2010. 128 p. Dissertação (Mestrado) - Fundação Getúlio Vargas, Rio de Janeiro, 2010.

SOUSA, W. M. V. As percepções de comportamentos éticos e de justiça: seus impactos no elo afetivo indivíduo-organização. 2005. 93 f. Dissertação (Mestrado) - Universidade Federal de Uberlândia, Uberlândia.

WAGNER III, J. A.; HOLLENBECK, J. R. Comportamento organizacional. São Paulo: Saraiva, 2006.

WITT, L. A.; BROACH, D. Exchange ideology as a moderator of the procedural justice: satisfaction relationship. The Journal of Social Psychology, Heldref, v. 133, n. 1, p. 97-103, Feb. 1992.

WITT, L. A.; WILSON, J.W. Income sufficiency as a predictor of job satisfaction and organizational commitment: dispositional differences. The Journal of Social Psychology, Heldref, v. 130, n. 2, p. 267-268, Apr. 1990. 